Vol. 2, No. 2 | July - December 2019

\title{
Bio Methane from Biogas, Renewable Energy Resource for Pakistan
}

\begin{abstract}
Asif $\mathrm{Ali}^{1}$
Abstract:

The major barriers in development of Pakistan's economy are dependency on inefficient and unaffordable energy technologies, thus it is an energy-short country. The future energy demands of the country can be fulfilled by opting renewable energy technologies. The number of biogas energy generation Systems is increasing steadily, as they are generated with low-cost. Pakistan's $70 \%$ population is residing in rural areas, so biogas energy can be a good substitute. A national policy regarding the development of biogas energy technology is needed to enhance the biogas potential. This study focuses on control of agriculture waste by chemical absorption process, in which the biomass is converted into fuel. In this way not only, biomass is treated but renewable energy can be generated. The raw material, biomass, was fed to an anaerobic digester that operates at $35^{\circ}$ and produces biogas along with sludge biomass. The mixture of biogas and sludge biomass was separated with the help of flash unit and further separation was done by centrifuge to get concentrated biomass and water. The raw biogas was compress from 1 bar to 5 bars in order to remove ammonia from biogas. The biogas was upgraded to bio methane in an absorption column by treating biogas with potassium hydroxide. The biomass potential of Pakistan which is 853,500 tons/day can be utilized by using this process to generate 469,425 tons/day of bio methane. Cost analysis indicated that the chemical absorption is feasible.
\end{abstract}

Keywords: Biogas, Hydrogen sulfide, Chemical absorption, Potassium hydroxide, Bio methane, Renewable energy.

\section{Introduction}

\subsection{Energy Situation in Pakistan}

Pakistan is facing energy crises, major energy resources are oil and gas, the country's reserves of oil and gas are finite and hence oil is imported on a very large scale. The oil imported, covered approximately $31 \%$ of the country's energy necessity. The oil import bill of Pakistan increasing year by year, from it was

about $\$ 7$ billion and increase to $\$ 12$ billion in 2011.

The conventional energy sources provide more than $99 \%$ of the energy and only $1 \%$ energy supply is from renewable sources. For the year 2010-2011, aggregate energy consumption was 38.8 million tons of oil, of which $38.5 \%$ was used up by the industrial sector, $30.9 \%$ was consumed by transport, and agriculture only used $2 \%$ of the total intake. [1]

\footnotetext{
${ }^{1}$ Department of Renewable Energy Engineering, USPCAS-E, Peshawar *Corresponding Author: chemasif85@gmail.com SJET | P-ISSN: 2616-7069 | E-ISSN: 2617-3115 | Vol. 2 | No. 2 | @ 2019 Sukkur IBA
} 


\subsection{Renewable Energy}

Renewable Energy is described as the form of energy which resources are naturally and can be replaced on a human timescale. The conventional (non-renewable) sources of energy are depleting at a faster rate day by day and this drawback is leading to move towards the renewable energy. Renewable energy has a vast potential to cover our future energy demands and overcome worldwide energy crisis. The natural resources of renewable energy include; wind, biogas, tides, rain, geothermal heat and sunlight, etc.

Availability of renewable energy resources over wide geographical regions differentiate it from other conventional energy sources, which are limited to a few countries.

Another main advantage of using renewable resources is that, air pollution caused by burning of fossil fuels, can be controlled and develops public health by reducing sickness ratio caused by pollution and save linked health costs. [2]

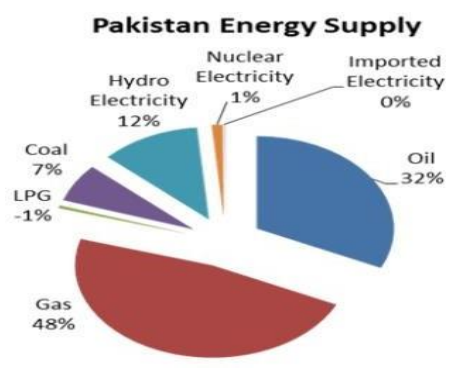

Fig 1: Pakistan Energy Supply by source

\section{Energy Consumption}

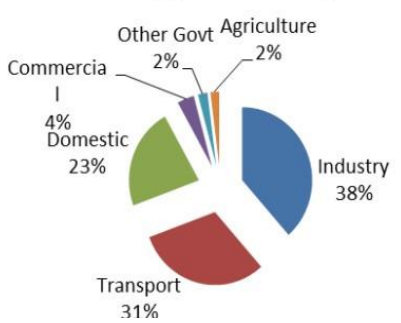

Fig 2: Pakistan Energy Consumption by sector

\subsection{Biogas}

A blend of various gases collected by the disintigration of organic matter in the absence of oxygen is known as biogas. Agriculture waste, municipal waste, plant material, sewage, food waste, and animal waste etc. are the raw materials from which biogas can be extracted.

The biogas composition is mostly composed of methane $(\mathrm{CH} 4)$ and carbon dioxide $\left(\mathrm{CO}_{2}\right)$ and addition to this, insignificant quantity of hydrogen sulfide $\left(\mathrm{H}_{2} \mathrm{~S}\right)$, moisture and siloxanes may have also present in the biogas. The methane, and other gases, hydrogen, and carbon monoxide can be combusted or oxidized with oxygen. This energy release upon combustion let biogas to be used as:

- Fuel

- Heating purposes

- Gas engines [3]

The waste can be treated by several processes:

- Open air windrow composting

- Incineration

- Landfill

- Mechanical biological treatment

- In-vessel composting

- Anaerobic digestion. [4]

Table I: Composition of Biogas

\begin{tabular}{|l|l|}
\hline Gases & Percentage \% \\
\hline Methane & $50-75$ \\
\hline Carbon dioxide & $25-40$ \\
\hline Nitrogen & $0-10$ \\
\hline Hydrogen & $0-1$ \\
\hline Hydrogen sulfide & $0-3$ \\
\hline Oxygen & $0-2$ \\
\hline
\end{tabular}

\subsection{History of Biogas in Pakistan}

The history of biogas in Pakistan is almost fifty-nine years old. In 1969, the first farmyard manure plant was buildup in Sindh to produce biogas from animal and farm waste. The Government of Pakistan inaugurated total

Sukkur IBA Journal of Emerging Technologies - SJET | Volume 2 No. 2 July - December 2019 @ Sukkur IBA University 
4,140 biogas plants under a comprehensive biogas scheme in 1974 up-to 1987. In 1982 to 1985, one thousand biogas plants were installed in several districts of Punjab. Another seven hundred and fifty family size biogas plants were installed all over Punjab as a scheme a program 'Adaptation of biogas technology to mitigate the energy crises' of agriculture department in 2009-2010. [5]

\subsection{Biogas Potential in Pakistan}

Biogas may be beneficial to overcome the present energy disaster in Pakistan and its cost is 35 to 50 percent less than that of other energy resources like, charcoal, kerosene oil and firewood. Nowadays a big problem in Pakistan is energy crises and it could be handled by enriching livestock and dairy development. Animal dung can be utilized for the production of gas and a high-quality fertilizer as a byproduct. Pakistan has approximately 29.9 million buffalos, 33 million cattle. One buffalo or cow produces 15 $\mathrm{kg}$ dung per day and there are 56,900,000 animals and if 50 percent of this dung is collected, then $426,750,000 \mathrm{~kg}$ of dung every day is available for the conversion to biogas. A biogas plant can install within Rupees 40,000 to Rupees 150,000 and its components are easily attainable in the local market. [6]

\subsection{Bio Methane}

The upgraded form of biogas by removing traces like, hydrogen sulfide, carbon dioxide and moisture is known as bio methane. Biogas is the product of anaerobic digestion of raw materials like dead plant material, manure, sewage, organic waste, etc.

Although its usability is recognized for fairly some time, bio methane might be used as a possible source of energy, specifically for fossil fuels. Installation of plants for the producing of bio methane is new and initiated only in the recent years as an end result of the mounting prices of natural gas and high electricity prices. Bio methane and fossil fuel derived methane has a great difference between each other even though the certainty that both are originated from organic matter, and are same chemically.
The source of fossil fuel derived methane is old fossil residue of organic matter that lies buried deep in the ground from thousands or millions of years. While for the bio methane resources are "fresh" organic matter, available everywhere worldwide which marks it a renewable source of energy. [7]

\subsection{Different Technologies for Upgrading Biogas to Bio Methane \\ 1.7.1 Water and Polyethylene Glycol Scrubbing}

As carbon dioxide and hydrogen sulfide are more soluble in water than methane, water scrubbing is used to draw out these traces from biogas. In this method, traces are absorbed in a counter-current operation. First, the biogas is pressurized and then fed to a packed column from the bottom while at top, water is fed.

The water contaminated very quickly when high levels of hydrogen sulfide are to be treated which cause operational problem, thus stripping with it is not recommended. [8]

\subsubsection{Pressure Swing Adsorption}

In this method, few gas species are separated from a mixture of gases under pressure cohering to the specie's molecular characteristics and affinity for an adsorbent material. Special adsorptive materials (e.g. zeolites and active carbon) are utilized as a molecular sieve, which adsorb the intent gas species at high pressure.

An additional step is needed before PSA for the elimination of hydrogen sulfide, which is the main disadvantage of PSA technology. [9]

\subsubsection{Cryogenic Separation}

Carbon dioxide, hydrogen sulfide and all other biogas traces can be sort out from $\mathrm{CH}_{4}$ as each contaminant has specific temperature and pressure at which it liquefies. This segregation process requires low temperatures, near $-100{ }^{\circ} \mathrm{C}$, and high pressures, almost 40 bars. 
The requirement of substantial process equipment, such as compressors, turbines and heat exchangers are the main disadvantage of this process. [10]

\subsubsection{Membrane Separation}

In membrane separation the raw gas is passed through a thin membrane, some constituents are filtered out while the remaining components of the raw gas are accumulated at the surface of thin membrane. A ratio between high methane purity and high methane yield in the customized gas is created.

Relatively low methane yield and high membrane cost are the disadvantages of the membrane separation. [11]

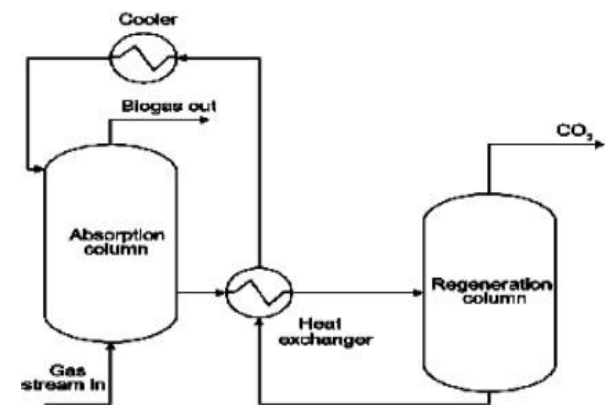

Fig 3: Chemical Absorption Method

\section{Methodology}

Several researchers have worked on the different techniques used for the customization of biogas to bio methane. Some of these methods are already discussed in the introduction section. According to literature review the feasible, economical, and environmentally friendly technique is chemical absorption. Availability of several absorbents, like $\mathrm{KOH}, \mathrm{NaOH}$, and MEA used in this process is another advantage of chemical absorption. According to Grazia Leonzio, among these absorbents $\mathrm{KOH}$ is the suitable one, having low price and less environmental impact. [12]

\subsection{Chemical Absorption}

Reversible chemical bonds are developed between the solute and the solvent in chemical absorption. Therefore, with a high energy input, regeneration of the solvent includes splitting of these bonds. Chemical solvents are normally either aqueous solutions of amines (i.e. mono-, di-, or tri- ethanol amine) or aqueous solution of alkaline salts (i.e. sodium, potassium and calcium hydroxides).

Almost complete removal of hydrogen sulfide is one of the major advantages of chemical absorption, also high efficiency and tendency to operate at low pressure are considerable advantages of chemical absorption. This process is generally used in industrial applications, and many other applications, such as natural gas purification. [13]

\subsection{Potassium Hydroxide (KOH)}

The absorbent used in this process is potassium hydroxide, generally called caustic potash which is an inorganic compound. Due to its reactivity toward acids it has many industrial applications, most of which accomplishing its corrosive nature. $\mathrm{KOH}$ is remarkable as the precursor to most soft and liquid soaps as well as several chemicals which contain potassium. [14]

\subsection{Overall process flow diagram}

The raw material, agriculture waste as biomass, and water was fed to an anaerobic digester that operates at $35{ }^{\circ} \mathrm{C}$ and produces biogas along with sludge biomass. The mixture of biogas and sludge biomass was separated with the help of flash unit and further separation was done by centrifuge to get concentrated biomass and water. The raw biogas from the flash unit was compress from 1 bar to 5 bars in order to remove ammonia from biogas. The biogas was upgraded to bio methane in an absorption column by treating biogas with potassium hydroxide. 


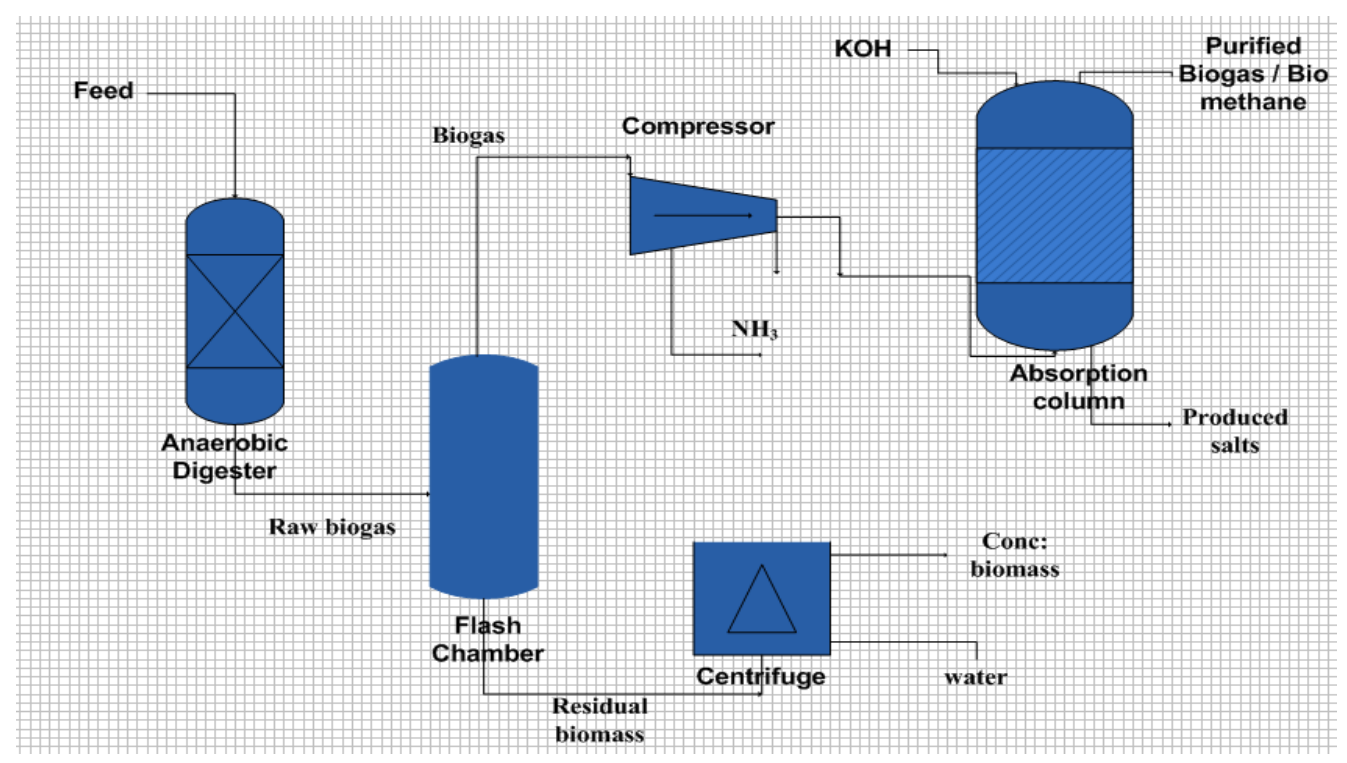

Fig 4: Overall Process Flow Diagram

100 tons/day of biomass and $70 \%$ conversion of biomass is taken as basis. Material and energy balances are applied on each unit by considering the following assumptions:

- Mostly Theoretical based

- Steady state Process

- $\Delta \mathrm{w}=\Delta \mathrm{K} . \mathrm{E}=\Delta \mathrm{P} . \mathrm{E}=0$

- $\quad 98 \%$ Flash separation efficiency

- $80 \%$ centrifuge efficiency

For material balance the following equation is used:

Input + Generation $=$ Output + Accumulation + Consumption

For energy balance the following equation is used:

$\mathrm{Q}=\sum \mathrm{m}_{\mathrm{i} \text {, out }} \mathrm{x} \Delta \hat{\mathrm{H}}_{\mathrm{i}, \text { out }}-\sum \mathrm{m}_{\mathrm{i}, \text { in }} \mathrm{x} \Delta \hat{\mathrm{H}}_{\mathrm{i}, \text { in }}$

Physical data such as different specific heat capacities used in the stoichiometric calculations is taken from 'Elementary Principles of Chemical Processes by Richard M. Feldar'[15], while Thermodynamic data such as different enthalpies, from 'Fundamentals of Thermodynamics by
Michael J. Moran \& Howard N. Shapiro'[16]

The main reaction occurring in the anaerobic digester is:

$$
\begin{aligned}
& \mathrm{CH}_{1.7} \mathrm{O}_{0.35} \mathrm{~N}_{0.1} \mathrm{~S}+0.975 \mathrm{H}_{2} \mathrm{O}-----\rightarrow \\
& 0.3375 \mathrm{CH}_{4}+0.6625 \mathrm{CO}_{2}+0.1 \mathrm{NH}_{3}+\mathrm{H}_{2} \mathrm{~S}
\end{aligned}
$$

\subsection{Individual Equipment Design}

Length, diameter and volume for each equipment are calculated by using residual time and L/D ratio from literature, specific for each unit. For example, for the anaerobic digester:

Residual Time $=10$ days

$$
\mathrm{L} / \mathrm{D}=1.7 \text { [17] }
$$

Volume $=$ Residual Time $\mathrm{x}$ Volumetric Flow Rate

\subsection{Cost Estimation}

Cost is calculated for each unit by using the following formulas, and the cost is estimated for the whole process to calculate the payback period of the unit. 


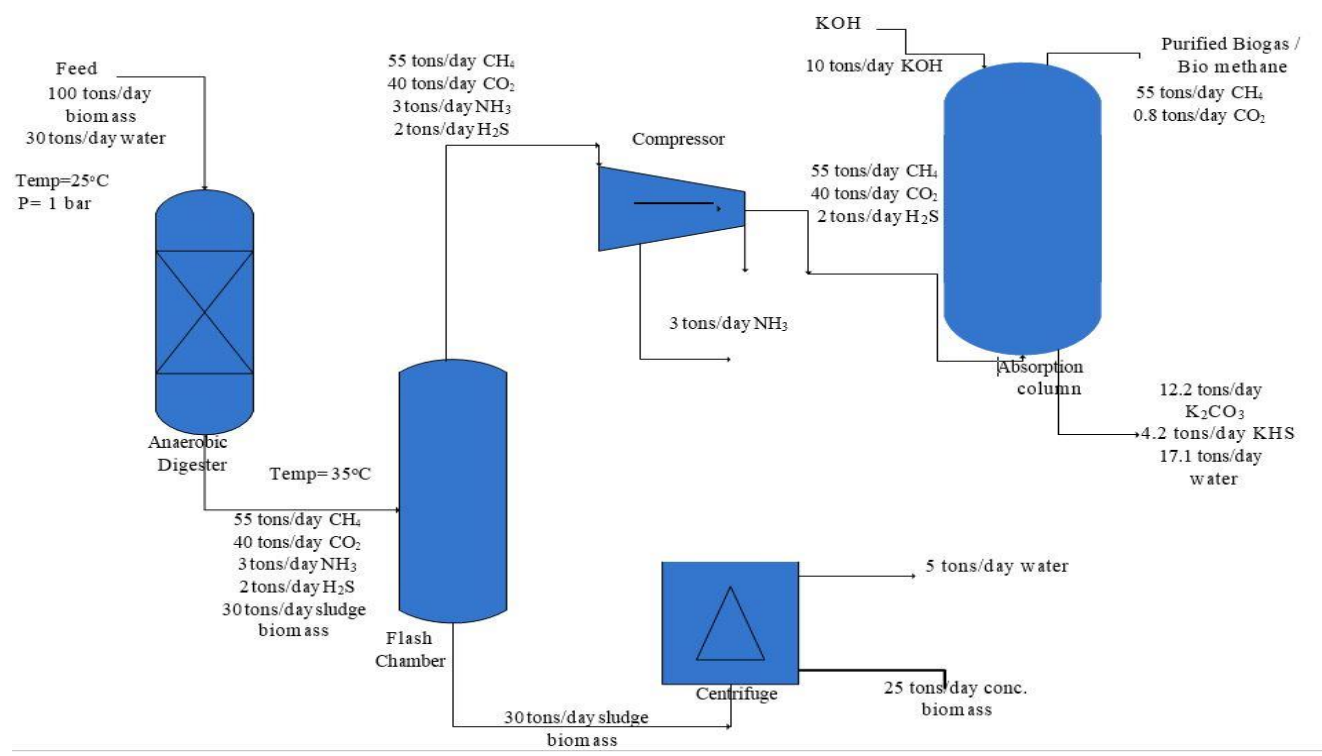

Fig 5: Overall Process Flow Diagram with Material Balance

- $\mathrm{C}_{\mathrm{E}, 1} / \mathrm{C}_{\mathrm{E}, 2}=$ Index $1 /$ Index 2

- Total Equipment Cost (TEC) $=\mathrm{C}_{\mathrm{E}, 2}$ $f_{M} f_{P} f_{T}$

$$
\mathrm{C}_{\mathrm{F}}=\sum_{i} f_{\mathrm{M}} f_{P} f_{T}\left(1+f_{P I P}\right) \mathrm{C}_{\mathrm{E}}+\left(f_{E R}+f_{I N S T}+f_{E L E C}\right.
$$$$
+f_{\text {UTIL }}+f_{O S}+
$$$$
\left.f_{B U I L D}+f_{S P}+f_{D E C}+f_{C O N T}+f_{W S}\right) \sum_{i} \text { CE [18] }
$$

\section{Results}

\subsection{Bio Methane}

We have developed this process for an industrial scale and cannot use this process in laboratory because of the unavailability of such kind of equipment in laboratories.

One of the best processes that we have selected is chemical absorption process in which biogas is upgraded to biomethane with the help of potassium hydroxide.

By this process, we have collected 55 tons/day biomethane as output, from 100 tons/day biomass feed. This biomethane is purified from traces like $\mathrm{H}_{2} \mathrm{~S}, \mathrm{CO}_{2}$ and $\mathrm{NH} 3$. The overall process as shown in figure 3.1 we have treated 55 tons/day of biomethane with 10 tons/day of $\mathrm{KOH}$ as absorbent. The absorbent $\mathrm{KOH}$ can be regenerated after treating with the biomethane in the form of produced salts. This regeneration of the absorbents makes this process economical and feasible.

The overall process is simulated by using COCO/COFE software. The input data and stream line compositions are adjusted in the flowsheet of COFE software, and then run the simulation. Figure 3.2 shows the simulation of the overall process.

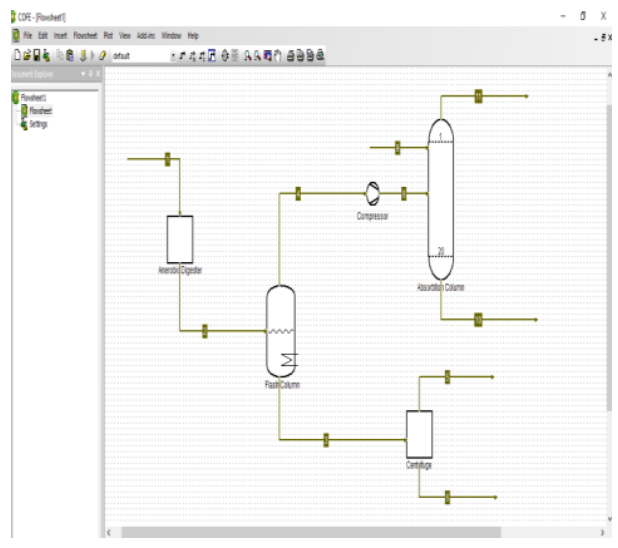

Fig 6: Simulation of the Overall Process 


\subsection{Individual Equipment Design Parameters}

Design parameters such as length, diameter and volume for each equipment are calculated as shown in the table. These parameters are calculated by using residual time and L/D ratio, taken from literature and mass flow rate from material balances around each equipment.

The compressor used in this up-gradation process is Single stage compressor [19], which Compression Ratio is 5. Minimum RPM required for the compression is 672 and the power required for the compressor is calculated to be $0.94 \mathrm{~kW}$

Table II: Equipment Design Parameters

\begin{tabular}{|l|l|l|l|}
\hline Equipment & $\begin{array}{l}\text { Length } \\
(\mathrm{m})\end{array}$ & $\begin{array}{l}\text { Diameter } \\
(\mathrm{m})\end{array}$ & $\begin{array}{l}\text { Volume } \\
\left(\mathrm{m}^{3}\right)\end{array}$ \\
\hline $\begin{array}{l}\text { Anaerobic } \\
\text { digester }\end{array}$ & 13.209 & 7.77 & 627.3 \\
\hline $\begin{array}{l}\text { Flash } \\
\text { Chamber }\end{array}$ & 0.24 & 0.08 & 0.185 \\
\hline Centrifuge & 3.84 & 0.48 & 3 \\
\hline $\begin{array}{l}\text { Absorption } \\
\text { column }\end{array}$ & 7.2 & 2.06 & 3.33 \\
\hline
\end{tabular}

\subsection{Payback period}

Total purchased equipment cost is calculated by estimating the purchased cost of each equipment, as shown in the table. Then total fixed cost for the whole plant was estimated. The values of several factors are taken from the literature.

Table III: Equipment Purchased Cost

\begin{tabular}{|l|c|}
\hline \multicolumn{1}{|c|}{ Equipment } & $\begin{array}{c}\text { Cost } \\
(\$)\end{array}$ \\
\hline Anaerobic Digester & 6437 \\
\hline Flash chamber & 3407 \\
\hline Centrifuge & 232 \\
\hline Compressor & 3277 \\
\hline Absorption Column & 6353 \\
\hline
\end{tabular}

The total fixed cost for the whole plant estimated is \$90600. Other costs such as maintenance cost, labor cost, Raw material cost, plant overhead, etc. as a factor of total fixed cost are estimated to be $\$ 11453$.

Taking Sale price as $\$ 0.45 /$ lge, [20], the payback period calculated for this plant is three years.

\section{Conclusions}

The biomass potential of Pakistan which is 853,500 tons/day can be utilized by using this process to generate 469,425 tons/day of bio methane. The technique used in this process for the up gradation of biogas to bio methane is environment friendly, as the $\mathrm{H}_{2} \mathrm{~S}$ gas is completely removed by treating the biogas with $\mathrm{KOH}$ absorbent. The waste from this process is a high-quality fertilizer, which is a byproduct of this process.

Table IV: Comparison Between Biogas and Bio Methane

\begin{tabular}{|l|l|l|}
\hline & Biogas & $\begin{array}{l}\text { Bio } \\
\text { methane }\end{array}$ \\
\hline Methane & $50-75 \%$ & $>97 \%$ \\
\hline $\begin{array}{l}\text { Carbon } \\
\text { dioxide }\end{array}$ & $25-50 \%$ & $<3 \%$ \\
\hline Oxygen & $0-2 \%$ & $<0.5 \%$ \\
\hline $\begin{array}{l}\text { Hydrogen } \\
\text { Sulfide }\end{array}$ & $<0-6000 \mathrm{ppm}$ & $<5 \mathrm{ppm}$ \\
\hline
\end{tabular}

The cost of bio methane compared to other energy resources, charcoal, kerosene oil and firewood is 35 to 50 percent less. The deforestation rate can be control by using bio methane as a heating source. Pollution like water, soil and air can be reduced by converting organic wastes to bio methane. All these benefits make this process feasible and sustainable.

There are several reasons for not utilizing the biogas potential. Some major reasons of them are that there is lack of awareness of the peoples about this technology, lack of training facility in this regard and follow up to address these problems.

Production of bio methane can be enhanced by establishment of biomethane directorate 
which will carry out the R\&D activities regarding the improvement of this technology. Information regarding bio methane generation and advantages is to be disseminated through print and electronic media to develop awareness of the people about this technology. Conduction of training sessions will be helpful to share the technical aspects of this technology. Coordination with international experts will be more fruitful for the development of this technology.

\section{REFERENCES}

[1] Amjid et all, 2011, "Biogas, renewable energy resource for Pakistan. Renewable and Sustainable Energy Reviews"; 15 (6), pages 2833-2837.

[2] Ellabban et al, 2014, "Renewable energy resources: Current status, future prospects and their enabling technology. Renewable and Sustainable Energy Reviews"; 39, pages 748-764.

[3] B.Bharathiraja et al, 2016 "Bio hydrogen and Biogas -An overview on feedstock's and enhancement process"; 810-828

[4] Iyyanki V.Muralikrishna "Environmental Management";Science and Engineering for Industry 2017, Pages 431-462

[5] Waqar Uddin et al, 2016 "Biogas potential for electric power generation in Pakistan: A survey"; pages 25-33

[6] www.blog.paksc.org, "Biogas can end Energy Crisis"; Retrieved October 2, 2016

[7] www.biomethane.org.uk, "What is Bio Methane"; Retrieved October 2, 2016.

[8] Wojciech M. Budzianowski, 2011, "Benefits of biogas upgrading to bio methane by high-pressure reactive solvent scrubbing, Biofuels", 6, pages 1220.
[9] Alonso-Vicario et al, 2010, "Purification and upgrading of biogas by pressure swing adsorption on synthetic and natural zeolites. Micro porous and Mesoporous Materials."; 134, pages 100-107.

[10] E. Ryckebosch, M. Drouillon, H. Vervaeren, 2011, "Techniques for transformation of biogas to bio methane. Biomass and bioenergy"; pages 16331645.

[11] Pradeep et al, 2016, "Biogas Upgrading Technologies: A Review. International Journal of Recent Technology Science \& Management", pages 2-4.

[12] Grazia Leonzio, 2016, "Upgrading of biogas to bio- methane with chemical absorption process: simulation andenvironmental impact. Journal of Cleaner Production"; pages 364-375.

[13] Pradeep et al, 2016, "Biogas Upgrading Technologies: A Review. International Journal of Recent Technology Science \& Management", pages 2-4.

[14] H. Schultz et al, 2005, "Potassium Compounds in Ullman's Encyclopedia of Industrial Chemistry".

[15] Richard M. Feldar "Elementary Principles of Chemical Processes"; pages 635-637.

[16] Michael J. Moran \& Howard N. Shapiro "Fundamentals of Thermodynamics"; pages 763-765.

[17] Abeam Khalid et al, 2011, "The anaerobic digestion of solid organic waste, Waste Management"; pages 17391744.

[18] Robin Smith "Chemical Process Design and Integration"; pages 17-33.

[19] www.gasequipment.com/catalogs/cryogen $\mathrm{ic/pdf/Blackmer/Compressors/Comp \% 20Sele}$ ction\%20and\%20Sizing.pdf, "Steps to compressor selection and sizing"; Retrieved January 24, 2017.

[20] www.irena.org/costs/Transportation/Bio methane 